\title{
118. The Enzymatic Degradation of Heme Proteins into Bile Pigments. XII
}

\section{The Characterization of the Final Reaction Product, a Possible \\ Precursor of Biliverdin, from Hemoglobin-haptoglobin as a Substrate due to Heme a-Methenyl Oxygenase. I}

\author{
By Osamu NaKaJima
}

\author{
First Department of Internal Medicine, Faculty of Medicine, \\ Kyushu University, Fukuoka \\ (Comm. by Naosuke ONodera, M.J.A., Sept. 12, 1963)
}

In the previous communication, ${ }^{1)}$ the isolation and characterization of the $656 \mathrm{~m} \mu$-absorbing substance, a possible precursor of biliverdin, by enzymatic degradation of pyridine-hemichromogen due to heme $\alpha$ methenyl oxygenase in the presence of NADPH and ferrous iron were described. From the results obtained, it was suggested that the 656 $\mathrm{m} \mu$-absorbing substance has an open tetrapyrrolic structure possessing a formyl group at the site of ring cleavage and contains an atom of iron.

It is the purpose of this communication to describe the characterization of the product from hemoglobin-haptoglobin as a substrate by the same enzyme. Evidence presented suggests that the tetrapyrrole part of this product is identical to that of $656 \mathrm{~m} \mu$-absorbing substance in structure and seems still to contain globin and haptoglobin in its molecule.

Experimental Procedure. Chemical. All chemicals were reagent grade materials from commercial sources.

Preparation of the Crude Enzyme. Adult male guinea-pig weighing 400 to 500 grams were decapitated, bled, and the livers were removed and chilled in ice. The livers were homogenized in four volumes of $0.1 \mathrm{M}$ phosphate buffer, $\mathrm{pH}$ 7.4, with a Potter-Elvehjem homogenizer. After a preliminary centrifugation at $10,000 \times \mathrm{g}$ for 15 minutes, the supernatant solution was further centrifuged at 105,000 $\times \mathrm{g}$ for 60 minutes. The supernatant finally obtained was referred to as the crude enzyme preparation.

Preparation of the Substrate. A solution of hemoglobin-haptoglobin complex was prepared by adding hemoglobin to a partially purified haptoglobin solution from human serum $\left(\mathrm{Hp}_{2-1}\right)^{2)}$ in an amount just sufficient to saturate the hemoglobin, and the correct amount was determined by paper electrophoresis according to Owen. ${ }^{3)}$

Formation of the 2,4-Dinitrophenylhydrazone. Besides the hydrochloric acid-ethanol solution or sulfuric acid-ethanol solution, a phos- 
phoric acid-ethanol solution of the 2,4-dinitrophenylhydrazine ${ }^{4)}$ was used as a reagent to avoid the use of the more reactive strong acids.

Paper Chromatograpy of the 2,4-Dinitrophenylhydrazone. Qualitative identification of the 2,4-dinitrophenylhydrazone from the reaction product was carried out on ethanol solution of the 2,4-dinitrophenylhydrazone by ascending paper chromatography on Whatman No. 1 filter paper by use of three different solvent systems. The hydrazones were located by spraying with a 10 per cent potassium hydroxide solution on the paper.

Several Qualitative Color Reactions. Several color reactions of heme compounds and bile pigments such as Gmelin's reaction, Ehrlich's aldehyde reaction, direct and indirect diazo reaction, and in addition aldehyde reactions such as Schiff's, ${ }^{5)}$ Tollen's, ${ }^{6)}$ and Benedict's ${ }^{7)}$ reaction were used to test the reaction product.

Infrared Absorption Spectra. These were made with suspensions in Nujol with the aid of Koken Type DS 201 infrared spectrophotometer.

Results and Discussions. A Large Scale Experiments. In order to obtain a sufficient amount of the product for characterization, a large scale experiment was carried out as follows: the reaction mixture consists of $20.0 \mathrm{ml}$ of $1.0 \times 10^{-3} \mathrm{M}$ human hemoglobin solution, $30.0 \mathrm{ml}$ of partially purified haptoglobin solution $\left(\mathrm{Hp}_{2-1}\right)$ just sufficient to saturate the hemoglobin, $50.0 \mathrm{ml}$ of $0.1 \mathrm{M}$ phosphate buffer of $\mathrm{pH}$ 7.4 , and $100.0 \mathrm{ml}$ of the crude enzyme preparation $(80.0 \mathrm{mg}$ protein per $\mathrm{ml}$ ) at a final volume of $200 \mathrm{ml}$. The mixture was incubated at $37^{\circ}$ and at $\mathrm{pH} 7.4$ aerobically under vigorous stirring. The reaction, when judged by oxygen uptake, was observed to terminate after 30 to 45 minutes of incubation.

Properties of the Final Reaction Product. It was failed to crystallize the reaction product at the present time because of the instability of this compound. However, several aldehyde reactions such as Schiff's, Tollen's, and Benedict's reaction were all positive with the reaction mixture, while negative with enzyme solution and hemoglobin-haptoglobin solution. Furthermore, 2,4-dinitrophenylhydrazone was obtained from the reaction mixture in a crystalline form and characterized as described below.

Formation and Properties of 2,4-Dinitrophenylhydrazone. After 30 minutes of incubation, $5.0 \mathrm{ml}$ of $0.25 \mathrm{M} \mathrm{2,4-dinitrophenylhydrazine}$ solution was added to the reaction mixture above mentioned. The solution was allowed to settle at room temperature $\left(10\right.$ to $\left.15^{\circ}\right)$ overnight. The precipitate formed was collected and dissolved in ethanol. The solution was kept at $70^{\circ}$ for 30 minutes, and the precipitate formed was centrifuged at $1,000 \times \mathrm{g}$ for 15 minutes. 
To the supernatant thus obtained, water was added until the solution became faintly turbid. The solution was then allowed to settle at room temperature, and the resulting precipitate was collected. The precipitate was dissolved in hot ethanol and water was added to the solution until it became turbid. After standing at $4^{\circ}$, crystals were obtained in yellow needles. These were recrystallized twice in the same manner.

The recrystallized hydrazone melted at 128 to $130^{\circ}$. An ethanol solution of the hydrazone exhibited single absorption maximum at $359 \mathrm{~m} \mu\left(\varepsilon_{m M}=30.5\right)$. Ascending paper chromatography of the recrystallized hydrazone was performed on Whatman No. 1 filter paper using three solvent systems. The results are summarized in Table.

Table. Paper chromatography of the 2,4-dinitrophenylhydrazone

\begin{tabular}{|c|c|c|}
\hline Solvents & $\begin{array}{l}\mathrm{Rf} \text { of } 2,4-\mathrm{DNP} \text { of } \\
\text { the reaction product }\end{array}$ & $\begin{array}{l}\mathrm{Rf} \text { of } 2,4-\mathrm{DNP} \\
\text { of formaldehyde }\end{array}$ \\
\hline $\begin{array}{l}\text { 1. n-butanol: ethanol: } 0.1 \mathrm{~N} \mathrm{NaHCO}_{3} \\
\left(\begin{array}{c}10: 10 \text { volume })\end{array}\right.\end{array}$ & 0.85 & 0.83 \\
\hline 2. $\mathrm{NH}_{4} \mathrm{OH}$-saturated n-butanol & 0.77 & 0.75 \\
\hline $\begin{array}{l}\text { pyridine: ethanol: }: 0.1 \mathrm{M} \mathrm{NaHCO}_{3} \\
5: 3: 5 \text { volume })\end{array}$ & 0.82 & 0.80 \\
\hline
\end{tabular}

Ascending paper chromatography of the twice recrystallized hydrazone was performed on Whatman No. 1 filter paper using three different solvent systems. An ethanol solution of the hydrazone was applied to the paper. $\mathrm{Rf}$ values were compared with those of the 2, 4-dinitrophenylhydrazone of formaldehyde.

Elemental analysis was as follows:

$$
\mathrm{C}_{11} \mathrm{H}_{11} \mathrm{~N}_{5} \mathrm{O}_{5}
$$

Calculated: C 45.10, H 3.78, N 23.90

Found: $\quad$ C $45.16, \mathrm{H} 4.23, \mathrm{~N} 23.30$<smiles>O=[N+]([O-])[O-]</smiles>

From the elemental analysis it was presumed that the crystal obtained was a substance in which one mole of 2,4-dinitrophenylhydrazine was combined with one mole of a monopyrrole compound as shown above. This was partly supported by the determination of the molar extinction coefficient compared with the hydrazone from formaldehyde. This structure presumably arose by a splitting of the tetrapyrrole structure at the $\beta$-methenyl bridge with a concomitant splitting of the side chain of the pyrrole ring when the reagent reacts with the product. At the present time, no hydrazone possessing 
the tetrapyrrolic structure could be obtained. As reported previously, ${ }^{1)}$ the product formed by the enzymatic conversion of pyridine-hemichromogen due to the same enzyme also exhibited positive aldehyde reactions, and formed 2,4-dinitrophenylhydrazone. These two hydrazones are seemed to be quite analogous from the elemental analysis data, infrared absorption spectra (Fig. 1), and from the data of several other determinations.
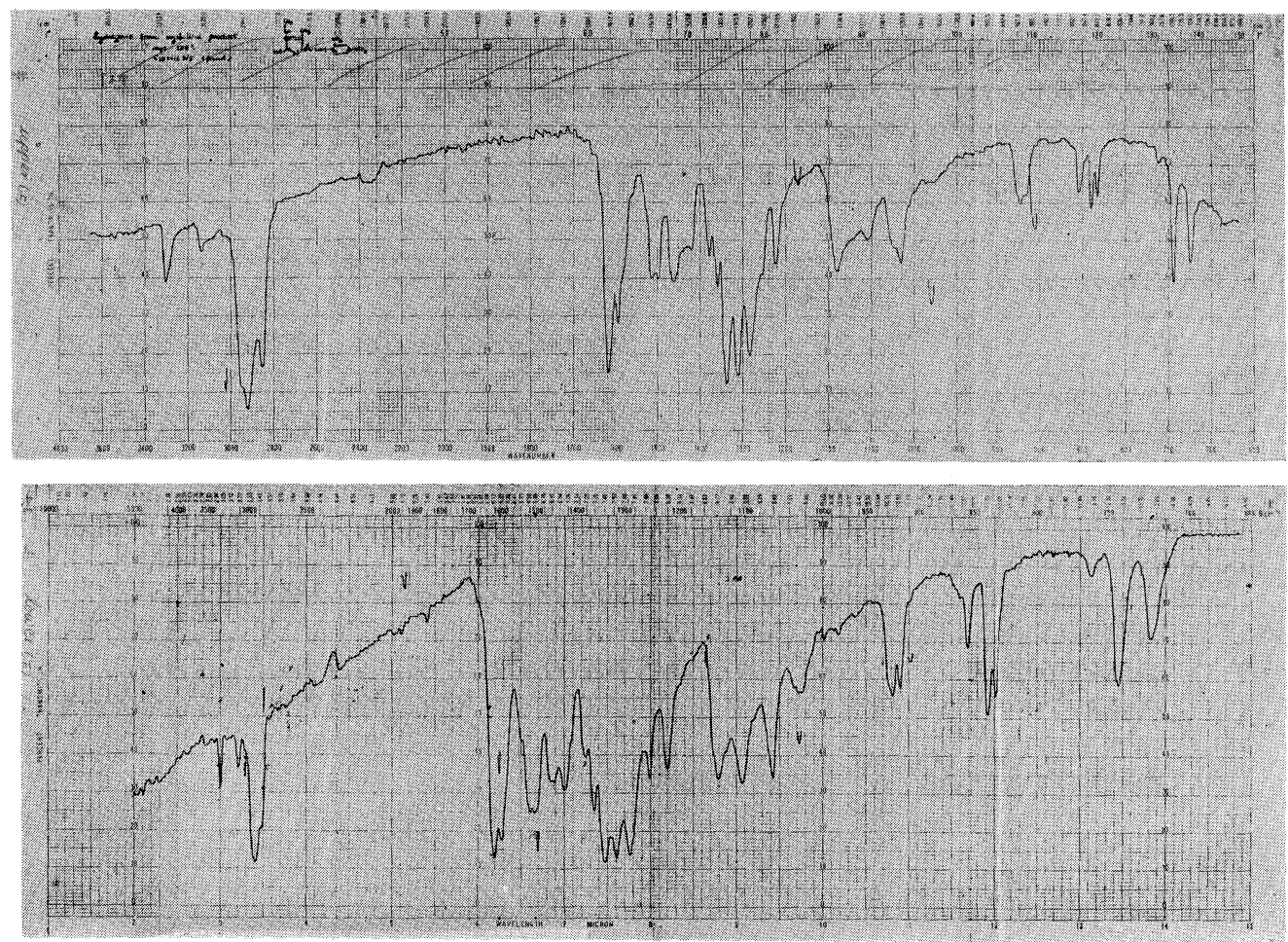

Fig. 1. The infrared absorption spectra of the 2,4-dinitrophenylhydrazone formed from the final reaction product of the enzymatic conversion of pyridine-hemichromogen (upper) and that formed from the product of the enzymatic conversion of hemoglobin-haptoglobin (lower).

From the evidence described here, it will be reasonable to postulate that heme part of hemoglobin-haptoglobin is cleaved enzymatically at $\alpha$-methenyl bridge and forms formyl radical at the site of ring cleavage. Proposed structure of the tetrapyrrole part of this final reaction product is presented in Fig. 2.

Summary. 1. The final reaction product obtained by the enzymatic degradation of hemoglobin-haptoglobin due to heme $\alpha$-methenyl oxygenase has been characterized.

2. The product was failed to crystallize at the present time, however, the structure of heme part seems to be analogous to $656 \mathrm{~m} \mu$ - 


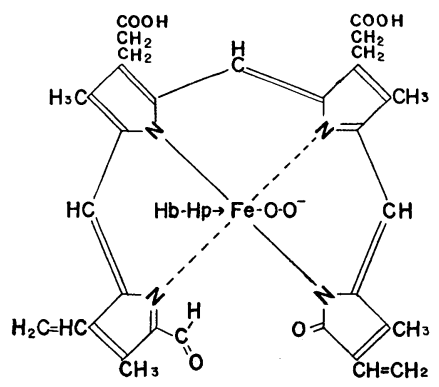

Fig. 2. Proposed structure of the tetrapyrrole part of the final reaction product formed from the enzymatic conversion of hemoglobin-haptoglobin.

absorbing substance, the product obtained by the degradation of pyridine-hemichromogen by the same enzyme.

Acknowledgment. The author is indebted to Professor K. Yamaoka, First Department of Medicine, Facutly of Medicine, Kyushu University, and Associate professor H. Nakajima, Department of Clinical Genetics, Tokyo Medical and Dental University, for their valuable advices and discussions during the course of this work.

This investigation was supported in part by a research grant (RG 9470) from the National Institutes of Health, United States Public Health Service and by the Scientific Research Fund of the Ministry of Education of Japan.

\section{References}

1) Nakajima, H.: J. Biol Chem., in press. (Received for publication, February 2, 1963).

2) Nakajima, H., Takemura, T., Nakajima, O., and Yamaoka, K.: J. Biol. Chem., in press. (Received for publication, February 2, 1963).

3) Owen, J. A., Silberman, J., and Got, C.: Nature, 182, 1373 (1958).

4) Johnson, G. D.: Amer. Chem. Soc., 73, 5888 (1951).

5) Tobie, W. C.: Ind. Eng. Chem., Anal. Ed., 14, 405 (1942).

6) Shriner, R. L., Fuson, R. G., and Curtin, D. Y.: The Systematic Identification of Organic Compounds, New York, p. 162, (1956).

7) Shriner, R. L., Fuson, R. G., and Curtin, D. Y.: The Systematic Identification of Oragnic Compounds, New York, p. 102 (1956). 